\title{
Artificial Structure and Its Specificity in the Development History of Epistemology
}

\author{
Yang Gao \\ School of Philosophy, Political Science and Law \\ Yunnan Normal University \\ Kunming, Yunnan, China
}

\begin{abstract}
The artificial structure is a kind of specifications, procedures and steps that must be conformed to in the cognitive activities, a kind of objective condition that must be met, the most reliable foundation, the highest guarantee of certainty, ultimate explanation and the benchmark that judges the knowledge. The epistemologists after Descartes always enjoy constructing the artificial structure and regard it as the requisite to understand the external word. However, whether such artificial structure exists in the actual cognitive process, it still needs to be solved. If there is no such structure, where the directions of epistemology will be? In fact, in the long course of the development of epistemology, the process of artificial structure from being structured to being negated has given enlightenment for Willard Quine, an American philosopher, which makes the study of epistemology enter into a new level.
\end{abstract}

Keywords—epistemology; artificial structure; particularity

\section{INTRODUCTION}

The artificial structure is a kind of constructed virtual presence which can make the epistemologists conduct further study on the human cognitive activities and knowledge itself, in this process, its specificity is not only deliberately added by people who want to achieve some purposes but also expresses certain willingness of people who pursue the knowledge activities and knowledge itself, therefore, a kind of construction-orient epistemology produces imperceptibly. However, whether such artificial structure exists in the actual cognitive process or not? If there is no such structure, where the directions of epistemology will be? Whether we abandon this artificial structure and take another chance for other fields or transform this structure to make it suitable for us to move forward on the current road, these problems still need to be solved.

\section{DEFECTS OF TRIPARTITE DEFINITION OF KNOWLEDGE}

From the tripartite definition about knowledge in the Theaetetus and Meno of Plato to the thoughts of epistemology of Descartes and Carnap, they generally belong to the epistemology of construction-orient. Usually, the structure is privileged or given special status in the whole epistemology, which shows that it can provide the foundation or explanation for the scientific knowledge or offer the highest guarantee for the certainty. Moreover, the exercise of main body to construct and give privilege or special status to structure is the human being. In other words, the epistemologists regard the artificial structure as the specifications, procedures and steps that must be conformed to in certain cognitive activities, a kind of objective condition that must be met, the most reliable basis, the highest guarantee of certainty, the ultimate explanation and the benchmark that judges the knowledge. In the cognitive activities, for all the restrictions of human self-capability and the produced objects that contradict to human self-capability, these structures will come into play at the right time and play a role from the outside of scientific knowledge. Meanwhile, as a kind of human self-capability, the structures will go to the eternal, infinite and absolute directions to supplement them continuously. The actual capacity of human beings has been enlarged in the process. And the results will be the "classical tradition" expounded by Russell in Our Knowledge of the External World, that is, the idea was formed from Socrates in Ancient Greek Times:

"For the rational, universal and simple belief... for example, they want to prove that all the realities belong to one and changes do not exist, and the sensory world is pure and illusory; the results obtained by them are bizarre but will not make them feel uncomfortable because they believe that their reasoning is correct. Then, people believe that the most striking and important truth about the whole reality can be established based on the validity that any adverse observation can not contradict it only by pure thoughts."

It is this kind of tradition that lays the foundation for a rational structure for later generations, and it has also laid a myth for certainty and foundation. The epistemologists have been puzzled by this myth (although it may be a kind of enjoyment to them), so the thoughts of epistemology of construction-orient can be popular in the river of long history of human intellect and progress. Whether the artificial structure or some similar objects really exist in the actual process of cognitive activities, I have many questions about it.

Whether the tripartite definition belongs to the structure of knowledge concept itself or not? The answer to this question leads to the consequences in two aspects. If the answer is affirmative, tripartite definition correctly explains the structure of knowledge, which is tantamount to tautology, at the same

Written by Russell, translated by Chen Qiwei: Our Knowledge of the Outside World [M]. Shanghai: Shanghai Translation Publishing House, 2008 
time, we still lack the exculpatory evidences that tripartite definition is the structure of knowledge concept itself, and this point is confirmed in the counter-example of tripartite definition; if the answer is negative, the structure of knowledge concept itself still has other different opinions or whether there are some other elements on the basis of tripartite definition, as thus, the tripartite definition does not completely reveal the structure of knowledge and also leave space for the latter multiple definition study. After the Gettier counter-example is put forward, it has cast considerable effects on the epistemology study at that time even today. In theory, Justified True Belief (JTB for short) is insufficient to define the knowledge, or ITB is inadequate as a definition of knowledge. Thereupon, more and more philosophers and epistemologists conduct further studies on this problem, and add the further restricted condition on the basis of JTB definition, so as to counter the threat caused by Gettier counter-example for the JBT definition of knowledge. The consequence is that on the basis of JTB, the definition of the additional restricted conditions, including the original JTB, has been constructed, at the same time, the new and more complex counter-examples also can be constructed, which shows the conditions constructed on the basis of JTB can not be defined as knowledge. But epistemologists always enjoy this game. On the one hand, this high-density creative activities have prospered the study of epistemology and made Gettier problem become the most important and core one in the contemporary epistemology, and this study still carries on until today; on the other hand, all kinds of opinions, views, documents and works have rapidly increased, so as to solve the Gettier problem. Moreover, this situation not only stimulates the traditional epistemology centered on the defense to present a new upsurge of research in the contemporary era, but also makes it easy for us to form a type of thinking. It seems that only the Gettier problem and defense theory are the most significant problems in the study of epistemology, which covers up other and "weird" thoughts viewed by traditional epistemology and contemporary believers. The foreign epistemologists mostly recognize Gettier counter-example, which makes people come up with question about the traditional JBT definition. Take Pollock for example, he thinks:

"The question of gaiter fundamentally changed the characteristic of contemporary epistemology. Many people study on epistemology consider that it is a central question, because it obviously prevents analyzing knowledge. However, we believe it represents an important but regrettable replacement of focus on epistemology. In history, the central problem of epistemology is defense but not knowledge. Philosophers in history is more interesting in how we know something rather than what we know. Of course, it is partly because they think it easy to answer the later question. However, the question of gaiter shows that is not an easy one to answer. ${ }^{2}$

Some domestic commentators think that the question of gaiter does not threat the JTB definition of knowledge. The gaiter itself is a question, and it is not important to JTB

Pollock, J. L., \& Cruz, J. (1999). Contemporary Theories of Knowledge $\left(2^{\text {nd }}\right.$ ed.). Lanham, Md.: Rowman \& Littlefield. pp. 13-14 definition. From the fact that revision of JTB and creation of new counter-example done by foreign learners of epistemology, which further indicates that the repaired definition still dissatisfies with the definition of knowledge, there is still no specific answer to the question "what is knowledge". Knowledge lacks of an abundant and specific definition, which means we need to think. Whether it is suitable to maintain that JTB definition supported by traditional epistemology and the practice regarded defense as the center, whether we should change the direction to think. As for this, I don't think it's more of a matter of the fact that JTB definition is suspicious; it is the traditional epistemological approach should be questioned. The reason for this is that we have been able to clarify the meaning of what we consider as knowledge in a brief moment. How should we regard that JTB definition and some later advanced revisions can apply to the new faith creating by the increasing unknown experience in the future, whether this definition accompanied with man's own willingness, which is imposed on the concept of knowledge so that being regarded as the structure of the knowledge concept itself. Reflecting on what we've been talking about in life, we can even guess that the "knowledge" has become a synthesis, mixed with habit, common sense and a series of results from inductive reasoning. Concerning for "faith", the definition of which is also ambiguity. Because it is a kind of creation by human's activities (materially or mentally), which are actually "belief". Then what is belief after all, a state of mind or merely an object of consciousness. In my opinion, philosophy and epistemology have no voice at all, further scientific research is needed. The question of "what we know" is more important than "how we know", because we cannot answer the second question without the answer of the first one.

\section{ARTIFICIAL STRUCTURE AND IT'S SPECIFICITY}

Descartes's role in the modern western philosophy is as same important as his theory of the expression of this kind of tradition, which is not only an extraordinary exemplify to human rationality, but also most sincerely pouring out to God by a devout disciple. If there is no God in his theory, then the idea of "I think" can be demolished by thought experiment. But the theory will lose the support when the idea "I think" is under suspicion. Therefore, the idea "I think" must be highest guaranteed by some kind of transcendental entity, then God appears. Of course, there's no doubt that Descartes is of strong scientific spirit. The conflict of learning and faith cannot be found from many great western philosophers, but a number of philosophers supplement each others. However, stand in the position of science itself, the theory of whether God exists or not cannot be proved or falsified. It's better to regard God as the hypothesis of transcendence because it is actually artificially entity. Moreover, before the influence left by the Middle Ages fades away entirely, the existence of this artificial entity and it's supremacy of authority cannot be easily denied by western cultivation. As for the absolute pursuit for certainty, it is not so much as the nature of knowledge itself (especially math and logic), rather vision of knowledge from human. When trying to obtain the knowledge by ourselves, we will realize that we lack the ability to do this; besides, whether these knowledge exist in our life or not and whether the world 
structured the same as we are imagining in the way suitable for our rational ability are questions contradictory to the ability of human. In other words, human's ability is limited, but the world is vast. Otherwise, the great gap between them can only be closed by create transcendental entity and entitled it with supreme ability, by which to bridge the gap between prospect and reality. Concept of God comes out from inference of selfcompletion.

Comparing to Descartes, structure activity in Xiumo's theory is less. Standpoint of empiricists is closer to science than rationalist, and motto of science is "There's nothing in the heart that is nonexistent in the feeling before". 3 The principle in the epistemology is wholly expressed in the result of Xiumo's theory: the legality of inductive reasoning, which is the challenge science is facing with. The criticism of Xiumo's theory is mild, just as the slightly use for structure by it. First of all, the difference between impression and ideas models to entire experience. Actually, experience will be strong or weak in degree, that is comparing the degree of stimulation at the moment to similar stimulation in memory and then recognize the strong and weak. But the criteria and activity of comparison can only be shaped and completed in one entity, and the result of the comparison expressed by degree adverbs cannot be concisely describe and correspond to the reality. The criteria is different from every entity, thus in this way Xiumo's concept theory lack of at least metrizability, accuracy, and the most important inter-subjectivity according to science and knowledge. Then, the division and explanation of the two kinds of knowledge is of some classic and tradition because of the lack of means, especially in the explanation between concepts. In practical matters, all of the knowledge explains to this aspect focuses on the argument for inductive reasoning, which is basic on psychologism eventually. Two important basic principles of science: inevitability of causality and legitimacy of inductive reasoning are finally proved on account of human's habitual association of the mind. Therefore, Xiumo said "we are not decided by rationality, but by habit or principle for association". "Thus, habit is a great guidance for life". If habit can produce scientific knowledge only by the combination of concept of experience then we can say it is because either the base of our scientific knowledge is not stable enough now or we are lucky. The common sense created by habit is just scientific knowledge nowadays, the difference between science and knowledge seems to be leveled off. Even if there are distinctions between them, science is argued by common sense will be the difference between them. Obviously, it is bad for science and meanwhile doesn't treat the position of each. "Science is not the substitution of common sense, but the extension of it". ${ }^{6}$ Also, "the difference between science and common sense is just the degree of

The Latin text is nihil in mente quod non prius in sensu. Quine, W. V. (1992). Pursuit of Truth (Rev. ed.). Cambridge: Harvard University Press., p. 19

Written by Xiumo, Translated by Guan Wenyun: The Treatise of Human Nature., p. 115 The Commercial Press., 1983

Written by Xiumo, Translated by Guan Wenyun: An Enquiry Concerning Human Understanding., p. 43 The Commercial Press., 1957 Press. p. 229 refinement of method". ${ }^{7}$ Three points left by Xiumo should pay attention to is: a thorough implementation of the principles of empiricism that fit into the spirit of science, how to explain problems of knowledge just depending on experience if not increasing artificial entity(no matter transcendental entity possessing privilege or some priori presupposition which can ensure the absolute certainty of knowledge, and lessons learned from difficulties encountered in scientific knowledge when demonstrate in the external scientific knowledge. It should be certain that Xiumo explore a new direction to search for problems of knowledge by analyzing human's mental habit. To some degree, Jingyin's thought of epistemology is continuing Xiumo's, which means to further improve the degree of refinement in the method and argument of causal and inductive reasoning.

\section{CONCLUSION}

"Modern philosophy believes that innate reasoning can explain the mysteries of the universe that other methods cannot find, and certify it's completely different from the way it appears to direct observation". ${ }^{8}$ Traditional way of thinking and preference to conducting systems are two famous labels pasted on Germanic people. "Miracles" are everywhere in the following transcendental epistemology of Kant and "rational reconstruction" by Rudolf Carnap. To solve the general inevitability and validity of mathematics and natural science in Kantian Epistemology resort to perceptual transcendental form of intuition and intellectual category. Knowledge becomes a compound combined of experience and priori form and category. Each scientific statement can be divided into composition of experience and priori, but only the combination of the two can be significant, otherwise it is meaningless. Thought will be empty without composition, intuition will be blind. This kind of expression of knowledge is the product of human's sensibility and intellectuality, and the embody of its action. But this kind of human's ability is not the scientific finding; it is discovered from the experiment of human's cognitive activities by complex analysis of Kant. The way to analyze is just as Russell said "because comparing to the extremely subtle, abstract and difficult argument, to prove the obvious fact that things in the world connect with each other is more likely to go wrong". 9 Moreover, knowledge expressed in this way means there are nonempirical component, which cannot be testified by experience, thus natural science is not pure. Whether human's cognitive ability is just as he says and comes into play in that way or not is a scientific question need to be researched and solved, but it is not a problem for Kant. Intellectuality is natural law, and nature must show me in this way. Revolution of Copernicus has solved the difficulties of expiricism and rationalism in cognitive, but run in the opposite direction of science. The positive meaning of Kant's construction of the thing in itself can be regarded as the reflection on the classical tradition. It's necessary to constrain

Quine, W. V. (1973). The Roots of Reference. La Salle, Illinois: Open Court. p. 129

Written by Russell, translated by Chen Qiwei: Our Knowledge of the Outside World., p.13, Shanghai Translation Publishing House, 2008.

Written by Russell, translated by Chen Qiwei: Our Knowledge of the Outside World., p.4, Shanghai Translation Publishing House, 2008 
human's rationality so that leave room for faith. But the negative meaning is whether the world actually exists in an ontological world or not. This is not what science is going to find, the requirement of science is just to report the fact: The thing is just like this.

Rudolf Carnap's construction has been discussed in the first chapter, in short, it is said that his rational reconstruction of the world is an effort for real philosophical activities, clarifying philosophical questions and exploring scientific knowledge. Rather, he has created a new world view. In his eye, the world is shown as sensory materials, symbolic logic and set theory so that it is entirely different from the world described in common words. In this world, Rudolf Carnap deploys forces and point country in his own scientific way. Failure of rational reconstruction is what should be learned by people with lofty ideas $\mathrm{n}$ the way to research philosophy, especially for whom researching in the field of epistemology. We must not go further on this road, and it's time for the classic curtain call. Failure of Rudolf Carnap provides a typical negative example in the aspect of human reconstruction, but it has positive meaning in terms of means. Surely, advances in mathematics and logic in twentieth century and by the efforts of Frege, Russell and others, applying to the original method of science to the study of philosophy, the language used in philosophy research is more accurate, so that reducing the ambiguity of statement and proposition in philosophy, which is fortunate for the whole human philosophy, especially for the study on epistemology. But it should be noticed that it is just the progress of research means, which is not means new artificial entity's born. The artificial entity here is created by human and possessing privilege of providing basic, deterministic and universal applicability and so on. However, it takes generations of efforts to move forward in means, which is beneficial for philosophy, science and even the progress of rationality and morality pursued by human. Therefore, it is suitable only if the mathematics and logical method utilized limitedly and reasonably in the study on epistemology, regarding it as means rather than gift of a priori knowledge or transcendental entity, which just inspire Willard Quine.

\section{REFERENCES}

[1] Written by Russell, translated by Chen Qiwei: Our Knowledge of the Outside World [M]., Shanghai: Shanghai Translation Publishing House, 2008

[2] Written by Xiumo, translated by Guan Wenyuan: The Treatise of Human Nature[M], Beijing: The Commercial Press., 1983

[3] Written by Xiumo, translated by Guan Wenyuan: An Enquiry Concerning Human Understanding [M], Beijing: The Commercial Press., 1957

[4] Pollock, J. L., \& Cruz, J. (1999). Contemporary Theories of Knowledge (2nd ed.). Lanham, Md.: Rowman \& Littlefield.

[5] Quine, W. V. (1992). Pursuit of Truth (Rev. ed.). Cambridge: Harvard University Press.

[6] Quine, W. V. (1960). Word and Object. Cambridge: The M.I.T. Press.

[7] Quine, W. V. (1973). The Roots of Reference. La Salle, Illinois: Open Court. 